\title{
Information Push Service of University Library in Network and Information Age
}

\author{
Song Deng ${ }^{1}$ and Jun Wang ${ }^{2}$ \\ ${ }^{1}$ Library, Beijing Jiaotong University, Beijing 100044, P.R. CHINA \\ sdeng@bjtu.edu.cn \\ ${ }^{2}$ School of Science, Beijing Jiaotong University, Beijing 100044, P.R. CHINA \\ wangjun@bjtu.edu.cn
}

\begin{abstract}
In the present paper, we study the information push service of university library in the age of network and information. Information push service is an information dissemination technology, and is a new kind of information service model in the network environment. Along with the rapid development of information, network and digital technologies, the push service of university library is important to the innovation of personalized services for the university library. In this work, we shall discuss and analyze the realizations of Internet-based information push services for university library.
\end{abstract}

Keywords: Information technology, network environment, digital technology, university library, push service, literature information

\section{Introduction}

Internet system has developed rapidly in the past years, this causes the extreme swelling of online information, so that it is not easy to find the useful information and useful data just like to find a needle in a haystack. Especially for the university academics, researchers and graduate students, the large numbers of valuable online information and database resources are not easy to be accessible. So readers and users eager to find a way to automatically obtain practical, accurate, refining and high-quality information and data in the ocean of information and data $[1,2,3,4]$. University library should seize this opportunity, take advantage of the information push technology in the network environment, by the information technology, the network environment and the digital technology, carry out the information push service, this is undoubtedly one of the best choices for university library services.

Along with the rapid development of information, network and digital technologies, the needs of readers and users (including the school students and the general readers) for literature information show the diversified, integrated and efficient trends $[1,2,3,4]$. So that the innovation and changing of service for university library attract much attentions of the librarians all over the world $[1,2,5,6,7,10,11]$. Much research work has been made to study and reform the management systems of university library $[3,4,8,9,12,13]$. In the present paper, we will study the information push service for the university library, and do the analysis on the various methods of push services, in order to improve the push service quality of university library, so that, to adapt to the needs for the rapid development of today's information society. 


\section{Description of Information Push Service in University Library}

Information push technology is an information dissemination technology, is a new kind of information service model in network environment. It is a technology, which is based on certain technical standards and conventions, and it selects the specific information automatically from the information resource, and through a certain way, it regularly passes the information to the users.

The essence of information push is using a special kind of software systems. The software can input the requested information (according to users' request) into the system in advance. This includes the user's personal information file, the user's personal information topics and the research direction. The system will be able to take the initiative to search the Internet for the information to meet the needs of the user, and after screening, classification and sorting, according to each user's specific requirements, the system will transfer the information to the user in an appropriate time. Information push service highlights the active service of information, i.e., change the past "people looking for information" as to be "information to find people". Through email, push channels, reservation website and many other ways (for example, network and mobile telephone, etc.), the specific information can be transferred to the specific people. Information push services can expand the scope of services, can improve service quality, and can meet the needs for the rapid development of information society.

\section{Domestic and International Devel- opments in Information Push Ser- vices}

Information push technology was first proposed by the PointCast company of
U.S.A. in 1996, and the PointCast became the first company to use the information push technology to transfer the information in the Internet. Subsequently many companies have introduced the distinctive "push" type software and related products.

In many foreign university libraries, the personalized services are carried out well. My Library of Cornell University is the most representative of personalized services. My Library-Cornell University Library of personalized service system is composed of three parts: MyLinks, Myupdates and Myecontents. Mylinks are the tools for the user's personal collection of digital resources and personal organizations. Myupdates are the tools for promptly notifying the user the new library resources, that is, one can input the request into Myupdates service system, the system will periodically retrieve the library union catalog, the new arrival information will be notified to the user in the form of an e-mail message. If the user needs to save the information data, he can use the Mylinks system, and the information can be organized into Mylinks, ready to become his own inquiries "folder". Mycontents are the third part of personalized service system, which were officially launched by Cornell University Library at August 27, 2002. Mycontents are the personalized journal directory information service, which use the filtering technology to solve the information overload and information garbage problem, thus they have improved the quality of recommendation.

There are some more representative personalized services in domestic university libraries. One is the infrastructure project-CNKI Project, which was cosponsored by Tsinghua University and Tsinghua Tongfang Knowledge of China in 2002. In CNKI Project, one function of TPI system is the actively push service, it can carry out the subscription-based push 
services, retrieval type push service and prompt type push service. Through these push services, users will be able to get all information without logging site to achieve a new access way "information to find the user". The other is the knowledge-based personalized recommendation service system-"Digital Library of Personalized Recommendation System" (DLPRS), which was jointly developed by School of Management and Library of Chinese People's University. The DLPRS uses the content-based recommendations and the collaborative recommendation technology, not only it can provide the information according to user's explicitly requests, but also it can automatically track a variety of information (which the user has accessed) to analyze the traces to obtain the user's interests and preferences (in the case that the user may do not participate in this system). Then this system can make the recommendation for the user. The recommended contents are the real collections of the library, including the OPAC system resources, introduction or purchase database resources, the characteristic self databases, network dynamic academic resources, etc.

\section{Methods of Implementing Infor- mation Push Service}

In the implementation process of information push service, firstly a register as a user login is needed; for the reader's specific needs, the system creates a user database for the user; regularly or randomly make the online information collection, screening, processing, establishment of resource processing integration system, to achieve the multi-type database format resources exchanging in each other in the local indexing; provide the various forms of retrieval and classification of navigation. Library information push service is implemented from scratch, is bound to be an initial implementation, and continuously enrich, improve and perfect the process. Therefore, it should be set up the library information push service team, which is responsible for setting the allied push service system, and gradually achieve the goal of information push service.

\subsection{Primary stage of information push service}

The realization of Internet-based information push services for university library can usually be taken in the following steps:

(1) E-mail form: This is now the most common and the simplest method. In email form, it takes the initiative to bring the latest information to the user. New library books and journals can be pushed in this way, and the library can also use this method to provide the electronic journals, the newspapers, the news subscription services. For this form, the reader can hold the form of notification, the time interval. This form does not have a strong interaction and mandatory, and the reader has less demanding for resources and information flows.

(2) The channel of information push service: Channel-type information push service is widely used as an online model, it will define some of the pages to be the browser channel. Readers may receive the interest and the information through the network broadcast, just like that one can select a TV channel and can specify the playback time. Here, information push service provides the active service, and is responsible for collecting information to create the channels of the content, and then pushing the information to the user; client component is primarily responsible for receiving incoming data and submission instructions, and data processing. Push service usually classify and organize the information, the large amount of information data are firstly 
pushed to the users, if the user needs to learn more about a particular aspect of the content of the information, then the information data can be acquired again. Therefore, this approach reduces the amount of transferred data, effectively improve the efficiency of access to the information. In fact, Microsoft, Netscape and Pointcast have the channel definition formats.

(3) The short message service of cellphone (SMS): SMS push is the synchronized push service, by this way we build the relationship among the readers and the dynamic relationship between the libraries, so that readers can get the timely information about the library, including the loan information, the expiration information, the reminder information, and the booking information, etc. And it can adopt and implement the interactive messages between systems for expiring and renewing books, appointments and other functions.

(4) The information push service of web design: In a specific page, the system can perform the push information to the readers, such as a company, an organization, a personal web page.

\subsection{The enriched phase of infor- mation push service}

(1) The special type information push service. This service is an Internet-based information push services, it uses the specialized software to send and receive the information, the information is pushed to the specialized audience. For the special type push service of library, it requires a proactive role in providing information for decision making, it can take the initiative to collect, process information and form decisions, then it can take the initiative to gather the information for deep processing, forming conclusions or reports, active mining, and accumulate new knowledge. The information which the customer booked and the dynamically generated will be pushed to the users, and we should create a library server database dynamic connection to the user, to perform the information push services in real sense and high-quality.

(2) Information push service from intelligent database system. User-style push: From the data manipulation of the user to start the information push. When a user manipulates the data, after the new modified data is deposited in the database, information push starts the process. Then the new push data is transferred to the other customers. Server push: The database triggers start up the information push. When the data changes, appearing to add, delete, modify operation, the trigger starts the process of information push.

\subsection{The improvement stage of infor- mation push service}

Simple RSS push service can not fully meet the demand of scientists for specialized information, library should address all key disciplines of the university, focusing on research and combined with library information gateway, to establish individualized professional style information push services. According to the actual needs of teaching, research and curriculum development, and around a particular topic of the user proposed, the system views, organizes the relevant information sources, and regularly provides the continuous information service. While the literature is pushed, it makes an effort to carry out secondary and tertiary literature development, and strive to provide readers with timely, efficient, highquality information resources.

The realization of information push service is not only related to the research frontier of information management theory, but also depends on information technology, computer technology, database technology and network technology development, is an interdisciplinary study. In this study, it should deeply study these 
basic techniques, apply these basic technology research results, to better carry out the high-quality information push service.

Information push service is a personalized proactive information service mode, new forms, push timely, widely applicable to the general user. This type of service can satisfy the personalized information needs of university teachers, researchers, students. It is also the active service of library staffs, one effective way to deepen the service, and the future direction of the library.

\section{Summary}

In this paper, we study the information push service of university library in the network and information age. We give the brief description of information push service in the university library, and comparatively study the information push services of domestic and international developments. We also investigate the methods of implementing information push service, especially for the services of Beijing Jiaotong University Library. This research displays that the push service of university library is important to the innovation of personalized services for the university library, and it also important to improve the service quality, to adapt to the needs for the rapid development of today's information society.

\section{Acknowledgements}

The authors were supported in part by National Natural Science Foundation of China Grant No. 71271026 and Grant No. 10971010. The authors would like to thank the support of the Library of Beijing Jiaotong University.

\section{References}

[1] S. Deng, J. Wang, "The Innovation of Service for University Library at the
Times of Networks," 2010 International Conference on Management Science and Engineering, pp. 398400, 2010.

[2] S. Deng, J. Wang, "New Approach of University Library Journal Service in Chinese University," 2010 International Conference on Management Science and Engineering, pp. 394397, 2010.

[3] S. Deng, Study on the Periodical of University Library in Information Age, University Library Development and Innovation, Southwest Jiaotong University Press, Xian, 2004.

[4] S. Deng, Improving the Utilization of Scientific Journals in Reading Literature Department, University Library Development and Innovation, Southwest Jiaotong University Press, Xian, 2005.

[5] G. Han, New Thoughts of College Library Journals Services in Information Era, INFORMATION SCIENCE, vol. 2, 2002, pp. 136-137, 2002.

[6] J. He, A Thinking on Academic Library Information Service Under Network Environment, Library, vol. 4, pp. 81-82, 2004.

[7] J. Huang, To Innovate the idea of Service and Improve it in Libraries, Library, vol. 2, pp. 70-71, 2004.

[8] Z. Huang, Change the Concept to Run a Library in Order to Promote Library Services as Key and Push the Library Cause Development of Our Country, Library, vol. 1, pp. 7-12, 2008.

[9] P. Lin, The modern library and the basic meaning of service innovation, RESEARCHES IN LIBRARY SCIENCE, vol. 3, pp. 69-71, 2004.

[10] S. Liu, Periodicals Work of Academic Library in Network Environment, INFORMATION SCIENCE, vol. 4, pp. 370-372, 2002. 
[11] X. Liu, On the Reader Service Work of Academic Library in the Network Age, Library, vol. 3, pp. 113-127, 2008.

[12] J. Yang, University Library Service innovation in the 21st Century, Library, vol. 1, pp. 58-60, 2004.

[13] B. Zhang, Reader Service of Library must Progress with Time, $\mathrm{Li}$ brary Tribune, vol. 4, pp. 157-158, 2004. 